\title{
Placing poverty-inequality at the centre of psychiatry
}

\author{
Peter Byrne, ${ }^{1}$ Adrian James ${ }^{2}$
}

BJPsych Bulletin (2020) 44, 187-190, doi:10.1192/bjb.2020.85

${ }^{1}$ Royal London Hospital; ${ }^{2}$ Royal College of Psychiatrists

Correspondence to Peter Byrne (peter. byrne@nhs.net)

First received 27 May 2020, final revision 17 Jul 2020, accepted 17 Jul 2020

(c) The Author(s) 2020. This is an Open Access article, distributed under the terms of the Creative Commons

Attribution-NonCommercial-ShareAlike licence (http://creativecommons.org/ licenses/by-nc-sa/4.0/), which permits non-commercial re-use, distribution, and reproduction in any medium, provided the same Creative Commons licence is included and the original work is properly cited. The written permission of Cambridge University Press must be obtained for commercial re-use.
We examine epidemiological evidence for the central role of inequalities (principally economic) in driving the onset of mental disorders, physical ill health and premature mortality. We locate the search for solutions in current UK contexts, and include known and likely effects of the COVID-19 pandemic. Prevention of mental disorders and adverse outcomes such as premature mortality must begin with efforts to mitigate rising poverty-inequality.

Keywords poverty; inequality; psychiatry; UK; developmental disorders.
We can't go on like this. As clinicians in the UK and elsewhere, we are asked to treat rising numbers of people with mental health problems - definitely not the 'worried well' but patients with life-changing mental disorders. Rates of adult mental disorders and addictions are high, and that 'disease burden' bears no relation to the resources allocated to address it internationally. ${ }^{1}$ Childhood mental disorders appear to be increasing, with rates of diagnosed illness of $15 \%$ in one large Danish cohort. ${ }^{2}$ We see higher rates of psychological and physical morbidity in older people and, despite many examples of good professional practice, older adults' teams do not receive the resources needed to manage these. ${ }^{3}$ Even if we receive the longpromised extra funding to treat people with mental disorders across their lifespan, our recent gains with \#ChoosePsychiatry will not deliver the numbers of psychiatrists we will need, let alone the nurses and other health and social care professionals. And so we look to prevention. Stopping these disorders from occurring, or reducing their severity, will reduce the distress of becoming unwell and alleviate the considerable costs to carers and wider society. Prevention is the first duty of the health system and those who work in it, on moral, ethical and sustainability grounds.

\section{Where do we start with prevention?}

Many would begin with adverse childhood experiences (ACEs). The original concept arose from a prospective study of childhood obesity, ${ }^{4}$ but their wider predictive value merits study. Hughes et $\mathrm{al}^{5}$ demonstrate increased relative risks in adults with four or more ACEs: doubled risks of heart disease (95\% CI 1.66-2.59), alcohol misuse (1.74-2.78), and cancer (1.82-2.95); tripled rates of chest diseases (2.47-3.77) and anxiety (2.62-5.22); a four-fold increase in 'low life satisfaction' (3.72-5.10) and depression (3.54-5.46); and a 30-fold increased risk of a suicide attempt (14.73-61.67). For selective or targeted prevention, we look at the other end of the (shorter) life of someone with severe mental illness (SMI); ${ }^{6}$ we might start with smoking, obesity, alcohol and substance misuse. All four shorten life expectancy and healthy years expectancy (life before multimorbidity begins) and make our task of improving quality of life in SMI even harder. Then there is a sixth area, fair access to medical care: current national strategies to improve physical health outcomes in people with SMI and treatment of all mental disorders focus on this. Older citizens, who began life as 'baby boomers', have acquired the nastier metaphor of a 'ticking time bomb' in terms of likely health and social care costs. The prevention of many dementias (vascular dementia, alcohol-related brain damage, head injury) is achievable. ${ }^{7}$ Seven challenges then, maybe for seven Royal College of Psychiatrists-led intercollegiate Committees? No, there is a better way. Behind all seven of these, Michael Marmot's 'causes of the causes', prevention has one major focus: poverty-inequality. 


\section{What are the consequences of poverty-inequality?}

'Inequality exists in the stresses and strains on family life, which shape the environment in which children grow up. It is the divergence in life expectancy between deprived and affluent areas, and the growing burden of poor mental health among disadvantaged groups'. ${ }^{8}$ In his accessible book, The Health Gap, Marmot ${ }^{9}$ concludes that the (health) gradient involves everyone, rich, poor and in between' (p. 26). Poverty is not inevitable, and 'in the US, after transfers and taxes, child poverty is higher than Lithuania - $23 \%$ compared with $15 \%$ - despite having similar levels of poverty pre-tax' (p. 137). Life expectancy, and specifically why this is falling in the UK (and was falling before COVID-19) among older and poorer citizens, is key to understanding why we need fundamental change. Marteau and colleagues ${ }^{10}$ studied the UK government's ambitions to reverse this rising mortality: 'the leading causes of years of life lost in England are tobacco use, unhealthy diet, alcohol consumption, and physical inactivity. All of these behaviours are socioeconomically patterned'. The scientific literature has reached a consensus on the health harms of poverty-inequality. In their study of multimorbidity in the ethnically diverse London borough of Lambeth (where a third of a million are registered with a general practitioner (GP)), Ashworth et $\mathrm{al}^{11}$ concluded that: 'acquisition of multimorbidity is patterned by socioeconomic determinants', with depression and asthma as early drivers of poor physical health. The US and the UK have similar high levels of inequality, and their inhabitants can expect to lose 7-9 healthy years (free from physical disability) by the age of 50 if they are poor, compared with their fellow citizens at the least deprived end of the gradient. ${ }^{12}$ All the evidence points to poor mental health, from common mental disorders through to SMI, as the means whereby poverty wrecks physical health.

\section{But rich people get mental disorders too}

Yes, they do. But they get better from depressive episodes faster and relapse less, in contrast to people on lower incomes, who have higher prevalence rates and worse outcomes. ${ }^{13} \mathrm{We}$ also concede that most people who grow up in poverty do not develop a life-changing episode of depression, let alone SMI. But the antecedents of SMI are complex, and our understanding of why people develop psychosis is changing, building on the seminal work of Jim Van Os on the toxic effects of urbanicity $^{14}$ - with consistent evidence of the cumulative effects of social disadvantage. Work with case-control groups in south London showed odds ratios (ORs) for subsequent psychosis in people below the poverty line of 4.50 (95\% CI 2.89-7.00) and 2.95 (1.89-4.61), for 1-year and 5-year pre-symptom onset, respectively. These ORs were the single highest predictors of psychosis, other than the related but confounded OR of 12.05 (7.13-20.35) for being unemployed on presentation to psychiatric services. ${ }^{15}$ Outcomes in adults with first-episode psychosis are complex and improving slowly in our professional lifetimes (with adequately resourced early intervention services); even at 5-year follow-up, Mattsson et $\mathrm{al}^{16}$ showed financial strain and social networks to be strong, independent predictors of outcomes.

\section{Lessons from history}

We cannot ignore poverty as a predisposing, precipitating and maintaining factor in most of our patients' disorders. Early in the neuroleptic era, we knew that poorer people had worse outcomes in schizophrenia, stayed in hospital longer, and were socially isolated even if they achieved discharge, ${ }^{17}$ but our textbooks called this 'social drift' despite prior debunking of the drift hypothesis. ${ }^{18}$ Hindsight is easy, certainly, but perhaps we should look to psychiatry's institutional bias. We still speak of a problem of stigma (negative societal attitudes) rather than acknowledging the reality that people with SMI have lower status conferred on them and face institutional obstacles to achieving their life goals, and calling this out as subcitizenship. ${ }^{19}$ At the time we started writing this, we welcomed the stated intention of the UK government to reverse a decade of austerity, signalled first in October $2018^{20}$ and often repeated during the first weeks of the spring 2020 lockdown. In advocating a broader role for busy psychiatrists in opposing regressive social policies, we are echoing the 'wake-up call' to colleagues from 2008: '[it is] fully consistent ... to think of psychiatry as being the only specialty in which its practitioners are fully trained doctors, incorporating psychology and socialbased knowledge and skills as major components of training. ${ }^{21}$ Not 'social workers with stethoscopes' but clinicians with public health knowledge who understand the environments in which our patients live. And die.

\section{What we know about the effects of COVID-19 (so far)}

COVID-19 has changed how every health professional practises. Each health specialty must play its part in mitigating and preventing further adverse outcomes. The virus leaves a trail of delirium, depression and anxiety, perhaps posttraumatic stress disorder in those who survive, ${ }^{22}$ and further misery for those bereaved. COVID-19 has revealed and exacerbated inequalities. Examination of death rates in the first 20283 hospital deaths with proven COVID-19 in England and Wales shows major differences between the richest and poorest regions: 'people living in more deprived areas [for example, the London boroughs of Newham and Brent, in the context of an early first peak in London] have experienced COVID-19 mortality rates more than double those living in less deprived areas. General mortality rates are normally higher in more deprived areas, but so far COVID-19 appears to be taking them higher still. ${ }^{23}$ At the time of writing, recording of the proportions of deaths among Black, Asian and minority ethnic (BAME) groups was incomplete, but preliminary figures, not least those for deaths among our BAME colleagues working in health and social care, have shown an excess. Health gradient differences are among the lessons of the pandemic: the age-standardised mortality rate of deaths involving COVID-19 in the most deprived areas across England was 55.1 deaths per 100000 population, compared with 25.3 deaths per 100000 population in the least deprived areas. ${ }^{23}$ We have yet to learn the full extent of excess deaths from COVID-19 among our patients across age groups, regions and specialties. It is too late for them, but we will 
not dodge the hard questions. As mental health professionals, we cannot remain as observers; we must now act on poverty-inequality.

\section{Solutions in this issue}

This issue opens with a contribution from two people with lived experience of SMI. Smoking remains a challenge in mental health services, and you will read about tobacco poverty and how to achieve more 'quits'. Housing First shows the evidence for changing how we approach this issue. We feature the Glasgow perspective on how we might progress, as well as an article on the cruelty of 'reforms' to the safety net benefits system. There is a biomedical perspective too.

\section{What have we left out?}

To name just five areas, we have not raised here the related premature mortality of people with personality disorders and intellectual disabilities, often worse even than that in people with SMI, ${ }^{6}$ nor the excellent work by patients, carers and professionals to reduce high-dose prescribing of psychoactive medications in intellectual disability. ${ }^{24}$ Health inequalities drive the UK's obesogenic environment, which is relevant to premature mortality in general but specifically to COVID-19 deaths. Cuts to addictions services are considered elsewhere, alongside the opioid crisis that has crossed the Atlantic. ${ }^{25}$

\section{Solutions beyond this issue}

As we mature as clinicians, our goals of intervention adjust to realities and hard-won experience. We do not see patients as a collection of neuroreceptors (including subtype and putative phenotype); we devise complex formulations to persuade patients towards self-management and empowerment, consolidating their (real not virtual) social networks and support systems. To achieve this, we will need to practise psychosocial education. Communicating complex information about the drivers of mental disorders might be easier if our patient has just one, but aetiology (causes of the causes) is shared. Beyond your wards and clinics, other health professionals also need to know what we know. Do our GP letters communicate the individual drivers of someone's misery (inadequate housing, precarious income, indeterminate status to remain, no locally available stop smoking services, the pressures of raising children when a parent has mental health or substance issues, etc.), or is it easier to write about medications and risk? It is a great start to identify what we can do better where we work $^{9,26}$ - and we cannot dispense social prescribing unless we understand our local communities.

\section{From public education to public engagement}

Do you know who leads on inequalities in your local organisations? Are there aspects of your practice where inequalities are making outcomes worse, and are you in a position to influence mitigation for these? Regional structures and local alliances have the potential to achieve results beyond the ephemeral 'levelling up' of current public discourse. Of course there will be political voices (of all shades and volumes) to keep us quiet, but we are 'following the science'. The Royal College of Psychiatrists has joined with many partners in Equally Well (www.equallywell.co.uk) to use the available evidence to reverse rising SMI mortality. We hope this special issue of the BJPsych Bulletin will get people thinking and talking. What will you do to achieve a wider societal dialogue? Our College and others are building resources to tackle poverty-inequality, but we need all the help we can get.

\section{About the authors}

Peter Byrne is a Consultant Liaison Psychiatrist at the Royal London Hospital; Associate Registrar in public mental health, Royal College of Psychiatrists; and Visiting Professor at the Centre for Health Policy, University of Strathclyde. Adrian James is President of the Royal College of Psychiatrists.

\section{Author contributions}

P.B. devised and wrote first drafts of this article to frame a special issue of the BJPsych Bulletin on poverty. A.J. commented on these drafts and enhanced the content on BAME inequalities and prevention.

\section{Declaration of interest}

P.B. remains the lead for public mental health at the Royal College of Psychiatrists, and represents the College in the Equally Well collaborative, hosted by the Centre for Mental Health; he is also a former Trustee of the Mental Health Foundation.

ICMJE forms are in the supplementary material, available online at https:// doi.org/10.1192/bjb.2020.85

\section{References}

1 Vigo DV, Kestel D, Pendakur K, Thornicroft G, Atun R. Disease burden and government spending on mental, neurological, and substance use disorders, and self-harm: cross-sectional, ecological study of health system response in the Americas. Lancet Public Health 2019; 4(2): e89-96.

2 Dalsgaard S, Thorsteinsson E, Trabjerg BB, Schullehner J, Plana-Ripol $O$, Brikell $\mathrm{I}$, et al. Incidence rates and cumulative incidences of the full spectrum of diagnosed mental disorders in childhood and adolescence. JAMA Psychiatry 2020; 77(2): 155-64

3 Royal College of Psychiatrists. Quality Network for Older Adults Menta Health Services Annual Report 2017-2019: CCQI 323 (ed Low R). RCPsych, 2019 (https://www.rcpsych.ac.uk/docs/default-source/improving-care/ccqi/quality-networks/older-adult-wards-qn/qnoamhs-annualreport-2017-2019.pdf?sfvrsn=13b5737b_2)

4 Felitti VJ, Anda RF, Nordenberg D, Williamson DF, Spitz AM, Edwards $V$, et al. Relationship of childhood abuse and household dysfunction to many of the leading causes of death in adults. The Adverse Childhood Experiences (ACE) Study. Am J Prev Med 1998; 14: 245-58.

5 Hughes K, Bellis MA, Hardcastle KA, Sethi D, Butchart A, Mikton C, et al. The effect of multiple adverse childhood experiences on health a systematic review and meta-analysis. Lancet Public Health 2017; 2 (8): e356-66

6 Chang C, Hayes RD, Perera G, Broadbent M, Fernandes AC, Lee WE et al. Life expectancy at birth for people with serious mental illness and other major disorders from a secondary mental health care case register in London. PLoS One 2011; 6(5): e19590. 
7 Grande G, Qiu C, Fratiglioni L. Prevention of dementia in an ageing world: evidence and biological rationale. Ageing Res Rev 2020. Available from: https://doi.org/10.1016/j.arr.2020.101045.

8 Joyce R, Xu X. Inequalities in the Twenty-First Century: Introducing the IFS Deaton Review. IFS, 2019 (https://www.ifs.org.uk/inequality/wp-content/ uploads/2019/05/The-IFS-Deaton-Review-launch_final.pdf).

9 Marmot M. The Health Gap: The Challenge of an Unequal World. Bloomsbury, 2015.

10 Marteau TM, White M, Rutter H, Petticrew M, Mytton OT, McGowan $\mathrm{JG}$, et al. Increasing healthy life expectancy equitably in England by 5 years by 2035: could it be achieved? Lancet 2019; 393: 2571-3.

11 Ashworth M, Durbaba S, Whitney D, Crompton J, Wright M, Dodhia H. Journey to multimorbidity: longitudinal analysis exploring cardiovascular risk factors and sociodemographic determinants in an urban setting. BMJ Open 2019; 9: e031649.

12 Zaninotto P, Batty GD, Stenholm S, Kawachi I, Hyde M, Goldberg M, et al. Socioeconomic inequalities in disability-free life expectancy in older people from England and the United States: a cross-national populationbased study. J Gerontol A Biol Sci Med Sci 2020; 75(5): 906-13.

13 Patel V, Burns JK, Dhingra M, Tarver L, Kohrt BA, Lund C. Income inequality and depression: a systematic review and meta-analysis of the association and a scoping review of mechanisms. World Psychiatry 2018; 17: 76-89.

14 Krabbendam $L$, Van Vugt $M$, Conus $P$, Söderström $O$, Abrahamyan Empson L, Van Os J, Fett AJ. Understanding urbanicity: how interdisciplinary methods help to unravel the effects of the city on mental health. Psychol Med 2020. Available from: https://doi.org/10.1017/S0033291720000355.

15 Stilo S, Gayer-Anderson C, Beards S, Hubbard K, Onyejiaka A, Keraite $A$, et al. Further evidence of a cumulative effect of social disadvantage on risk of psychosis. Psychol Med 2017; 47(5): 913-24.

16 Mattsson M, Topor A, Cullberg J, Forsell, Y. Association between financial strain, social network and five-year recovery from first episode psychosis. Soc Psychiat Epidemiol 2008; 43: 947-52.

17 Cooper B. Social class and prognosis in schizophrenia. Br J Prev Soc Med 1961; 15(1): 17-30.
18. Lapouse $P$, Monk $M$, Terris $M$. The drift hypothesis and socioeconomic differentials in schizophrenia. Ment Dis 1956; 46: 978-86.

19 Rowe M, Clayton A, Benedict P, Bellamy C, Antunes K, Miller R, et al. Going to the source: creating a citizenship outcome measure by community based participatory research methods. Psychiatr Serv 2012; 63: 445-50.

20 Mikhailova A, Hymas C. 'Austerity is over,' says Philip Hammond as $£ 12$ billion windfall sees spending increase. Telegraph 29 Oct 2019 (https://www.telegraph.co.uk/politics/2018/10/29/austerity-saysphilip-hammond-12-billion-windfall-sees-spending/).

21 Craddock N, Antebi D, Attenburrow MJ, Bailey A, Carson A, Cowen P, et al. Wake up call for British psychiatry. Br J Psychiatry 2008; 193(1): 6-9.

22. Rogers JP, Chesney $E$, Oliver $D$, Pollak TA, McGuire $P$, Fusar-Poli $P$, et al. Psychiatric and neuropsychiatric presentations associated with severe coronavirus infections: a systematic review and meta-analysis with comparison to the COVID-19 pandemic. Lancet Psychiatry 2020; 7(7): 611-27.

23 Office of National Statistics. Deaths involving COVID-19 by Local Area and Socioeconomic Deprivation: Deaths Occurring Between 1 March and 17 April 2020. ONS, 2020 (https://www.ons.gov.uk/peoplepopulationandcommunity/birthsdeathsandmarriages/deaths/bulletins/deathsinvolvingcovid19bylocalareasanddeprivation/deathsoccurringbetween1marchand17april),

24 NHS England. Stopping Over Medication of People with a Learning Disability, Autism or Both (STOMP). NHS England (https://www.england.nhs.uk/learning-disabilities/improving-health/stomp/).

25 Bhui K, Byrne P, Goslar D, Sinclair J. Addiction care in crisis: evidence should drive progressive policy and practice. Br J Psychiatry 2019; 215 (6): 702-3.

26 University College London Institute for Health Equity. Working for Health Equity: The Role of Health Professionals. UCL, 2013.

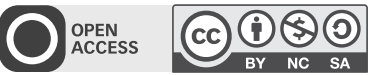

